\title{
Efeito do nível e do tamanho de impurezas nas propriedades físicas da massa granular de feijão
}

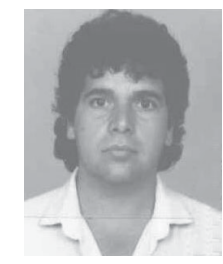

Paulo C. Corrêa ${ }^{1}$, Warley T. Guimarães ${ }^{2} \&$ Paulo C. Afonso Júnior ${ }^{3}$

1 DEA/UFV. C.P. 270, CEP 36571-000, Viçosa, MG. E-mail: copace@mail.ufv.br (Foto)

2 DEA/UFV. C.P. 270, CEP 36571-000, Viçosa, MG. E-mail: warley@alunos.ufv.br

${ }^{3}$ DEA/UFV. C.P. 270, CEP 36571-000, Viçosa, MG. E-mail: pjunior@alunos.ufv.br

Protocolo $031-24 / 03 / 2000$

Resumo: Objetivou-se, com o presente trabalho, determinar, experimentalmente, os valores de massa específica aparente e porosidade para grãos de feijão das variedades Carioquinha e Jalo, em função do nível e do tamanho de impureza na massa de produto, e ajustar equações matemáticas aos dados experimentais. Os resultados obtidos permitiram concluir-se que o aumento do nível de impurezas menores que os grãos provocou aumento da massa específica aparente e redução da porosidade e, com impurezas maiores que os grãos, ocasionou redução da massa específica aparente e aumento da porosidade da massa granular, para ambas as variedades estudadas. Os valores de massa específica aparente e porosidade da massa de grãos de feijão diferiram entre as variedades analisadas, sendo os valores da massa específica aparente da cultivar Carioquinha superiores, enquanto os valores de porosidade apresentaram-se inferiores aos observados para a cultivar Jalo, para o teor de umidade de $12 \%$ base úmida.

Palavras-chave: feijão, impureza, massa específica aparente, porosidade

\section{Effect of level and size of impurities on the physical properties of the granular mass of beans}

\begin{abstract}
The objective of this study was to determine experimentally the values of bulk density and porosity for grains of the Carioquinha and Jalo varieties of bean and to adjust mathematical equations to the experimental data, as a function of level and size of impurities in the product mass. The results obtained in this work point to the conclusion that the increase of the level of impurities smaller than the grains increased the bulk density and reduced the porosity, and that the increase of the level of larger impurities than the grains reduced the bulk density and increased the porosity of the granular product for both the varieties. The values of bulk density and porosity of the mass of bean grains differed among the analyzed varieties, the values of the bulk density of the variety Carioquinha being superior, while the porosity value was found to be inferior to that observed for the variety Jalo, for moisture content of $12 \%$ wet base.
\end{abstract}

Key words: bean, impurity, bulk density, porosity

\section{INTRODUÇÃO}

A cultura do feijão é de suma importância para o Brasil, uma vez que constitui, juntamente com o arroz, o milho e a mandioca, a base da dieta alimentar de grande parcela da população. O Brasil tem-se caracterizado como o maior produtor mundial de feijão, com uma produção de 2.914 .900 t na safra 1998/99 (CONAB, 1999) destinada quase que totalmente ao abastecimento do mercado interno, sendo o nível de exportação inexpressivo. Entre a diversidade de variedades existentes de feijão destacam-se, por seus atributos de qualidade e potencial de produção, as cultivares Jalo e Carioquinha, com produtividade média de $1.380 \mathrm{~kg} \mathrm{ha}^{-1}$ e $1.100 \mathrm{~kg} \mathrm{ha}^{-1}$, respectivamente (Ramalho et al., 1994).

Normalmente, a armazenagem de feijão tem-se limitado a atender à comercialização e à movimentação da safra e não à estocagem propriamente dita dos excedentes agrícolas. Colhido e beneficiado, o feijão é ensacado e guardado em simples depósitos ou armazéns, sem preparo eficiente nem condições adequadas para uma boa conservação; assim e em prazo relativamente curto, ele perde sabor e sofre modificações na textura, tornando-se pouco atrativo ao consumidor.

De acordo com Vieira et al. (1993) as características relacionadas à qualidade do feijão são alteradas pelas condições de armazenamento. Entende-se por qualidade a interação dos atributos de natureza genética, física, fisiológica e sanitária do produto. Para viabilizar a conservação do produto por longo tempo, algumas práticas se tornam necessárias, entre elas têm importante destaque as operações de limpeza, secagem e aeração, em razão de sua eficiência e rapidez em atender ao fluxo da produção agrícola; portanto, é de fundamental importância o 
conhecimento de propriedades físicas do produto, tais como massa específica aparente e porosidade, e a relação existente entre essas propriedades e os fatores responsáveis pela perda de qualidade do produto, para o desenvolvimento e operação de equipamentos para as principais operações pós-colheita.

Vários pesquisadores observaram, para diferentes produtos agrícolas, a influência de diversos fatores e processos que afetam a qualidade do produto sobre suas propriedades físicas, como temperatura do ar de secagem e teor de umidade do produto (Benedetti, 1987; Moraes Neto, 1991; Couto et al., 1999; Ruffato et al., 1999).

As impurezas são prejudiciais à conservação de produtos agrícolas, uma vez que impedem a movimentação do ar intergranular, favorecendo a concentração de calor e acelerando o surgimento e o desenvolvimento de insetos e microrganismos, além de dificultar a expedição e a comercialização do produto (Brooker et al., 1992).

Haque et al. (1978) e Grama et al. (1984) estudaram a resistência ao fluxo de ar, causada pela presença de impurezas na massa de milho, e concluíram que um teor maior de finos, materiais estranhos menores que os grãos, reduz a porosidade e eleva a queda de pressão estática ao longo da camada do produto, ressaltando que esta resistência ao escoamento de ar é inversamente proporcional ao tamanho das impurezas. Resposta semelhante foi encontrada por Chung et al. (1984) trabalhando com grãos de sorgo.

Sasseron (1980) observou, dentre as diversas propriedades físicas de produtos agrícolas, que a massa específica aparente e a porosidade sofrem notada influência do percentual e do tamanho de impurezas presentes na massa de grãos, enquanto Jayas et al. (1991) avaliaram a resistência ao fluxo de ar em camadas de sementes de linho, com diferentes tamanhos e percentuais de impurezas, verificando que o acréscimo de finos, em um nível de até $5 \%$, resultou em um aumento gradual da massa específica aparente; entretanto, as variações correspondentes à porosidade foram pequenas.

Ante o exposto, o presente trabalho teve como objetivo determinar, experimentalmente, os valores de massa específica aparente e porosidade, para grãos de feijão de duas variedades em função do nível e do tamanho de impurezas na massa de produto, e ajustar equações matemáticas aos dados experimentais.

O conhecimento das relações entre as propriedades físicas e os fatores de deterioração pode auxiliar na solução de problemas relacionados à transferência de calor e massa, durante as etapas de secagem e aeração, e para uma armazenagem correta do produto.

\section{MATERIAL E MÉTODOS}

Este trabalho foi realizado no Laboratório de Fenômeno de Transporte do Departamento de Tecnologia Rural, pertencente à Universidade de Uberaba, e no Laboratório de Análise e Tecnologia de Sementes da Empresa de Pesquisa Agropecuária de Minas Gerais (EPAMIG) localizado na cidade de Uberaba, MG.

As cultivares foram selecionadas em função das diferenças marcantes em suas propriedades físicas, principalmente na forma e tamanho, e pela importância econômica das variedades. Foram utilizados grãos de feijão (Phaseolus vulgaris L.), cultivares Jalo e Carioquinha. O produto em rama foi, depois de colhido manualmente, submetido a secagem em terreiro cimentado, até atingir o teor de umidade de aproximadamente $12 \%$ b.u.
Os teores de umidade do produto foram determinados pelo método da estufa, a $103 \pm 1{ }^{\circ} \mathrm{C}$, durante $72 \mathrm{~h}$, em três repetições (ASAE Standards, 1998).

Depois da secagem foi realizada, para cada cultivar, a trilha do material, quantificadas e separadas manualmente as impurezas, de acordo com o tamanho, em que partículas menores que os grãos, que passaram por peneira com crivos de $5 \mathrm{~mm}$ de diâmetro (impureza fina) e maiores ficaram retidas na peneira (impureza grossa).

Com o objetivo de se avaliar a influência das impurezas sobre a massa específica aparente e porosidade da massa de grãos nas cultivares estudadas, os tratamentos constituíram-se de um esquema fatorial $3 \times 4$, com três tamanhos de impureza (fina, grossa e mistura em partes iguais de impureza fina e grossa) e quatro níveis $(0,2,4$ e $6 \%)$ num delineamento inteiramente casualizado, com três repetições. Para cada tratamento foram utilizados em torno de $1.500 \mathrm{~g}$ de grãos por repetição, enquanto a massa específica aparente foi determinada com o auxílio de uma balança de peso hectolitro, da marca Dallemole, com capacidade de um litro, em três repetições para cada tratamento; por sua vez, a porosidade da massa de feijão foi determinada pela média de três repetições, utilizando-se um picnômetro de comparação a ar (Figura 1), construído no Departamento de Engenharia Agrícola da Universidade Federal de Viçosa, segundo o processo descrito por Day, citado por Mohsenin (1970).

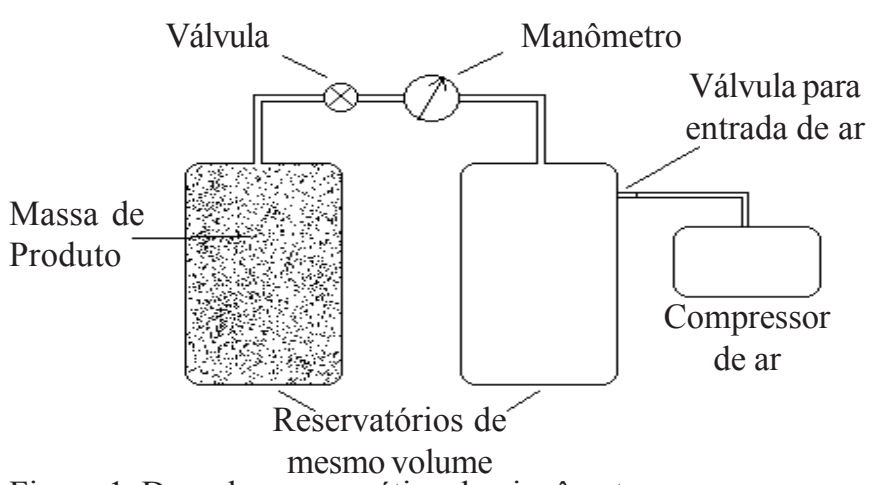

Figura 1. Desenho esquemático do picnômetro

Os dados foram inicialmente submetidos à análise de variância, em seguida procedeu-se à análise de regressão e seleção do modelo matemático adequado para expressar a relação entre as variáveis estudadas. Para o ajuste dos modelos matemáticos aos dados experimentais, utilizou-se o programa computacional STATISTICA 5.0, estimaram-se os valores dos parâmetros do modelo, em função da variável independente teor de impureza, para cada tamanho de impureza do produto.

Enfim, o grau de ajuste do modelo aos dados experimentais, baseou-se na magnitude do coeficiente de correlação ajustado, na significância dos coeficientes de regressão e na análise do comportamento da distribuição do resíduo, em função dos valores estimados.

\section{RESULTADOS E DISCUSSÃO}

O resultado da análise de variância, para as variáveis estudadas massa específica aparente e porosidade, mostrou que houve diferenças significativas $(\mathrm{p}<0,01)$ entre os tratamentos empregados no presente trabalho (Tabela 1) com exceção das interações variedade e teor de impureza, para ambas as variáveis e variedade, tamanho e teor de impureza, para porosidade. 
Tabela 1. Resumo da análise de variância para as variáveis massa específica aparente e porosidade

\begin{tabular}{|c|c|c|c|}
\hline \multirow[b]{2}{*}{ Causas de Variação } & \multirow[b]{2}{*}{ GL } & \multicolumn{2}{|c|}{ Quadrados Médios } \\
\hline & & $\begin{array}{c}\text { Massa Espec. } \\
\text { Aparente }\end{array}$ & Porosidade \\
\hline Variedade (V) & 1 & $80.356,390 * *$ & $273,663 * *$ \\
\hline Tamanho de Impureza (T) & 2 & $8.307,003 * *$ & $22,115 * *$ \\
\hline Teor de Impureza (I) & 3 & $694,781 * *$ & $0,602 * *$ \\
\hline $\mathrm{V} \times \mathrm{T}$ & 2 & $1.277,711 * *$ & $0,554 * *$ \\
\hline V x I & 3 & $25,987^{\text {n.s. }}$ & $0,253^{\text {n.s. }}$ \\
\hline $\mathrm{T} \times \mathrm{I}$ & 6 & $1.364,638 * *$ & $4,483 * *$ \\
\hline Vx Tx I & 6 & $188,712 * *$ & $0,125^{\text {n.s. }}$ \\
\hline Resíduo & 48 & 17,323 & 0,102 \\
\hline C.V. (\%) & & 0,5069 & 0,7648 \\
\hline
\end{tabular}

"* Significativo pelo teste $\mathrm{F}$ a nível de $1 \%$ de probabilidade

n.s. Não significativo pelo teste $\mathrm{F}$ a nível de $5 \%$ de probabilidade

Analisando-se os resultados apresentados nas Figuras 2 e 3 , nota-se que, de modo geral, a massa específica aparente aumenta e a porosidade diminui com o aumento do teor de impurezas finas; entretanto, a elevação dos teores de impurezas grossas promove redução da massa específica aparente e aumento da porosidade da massa de grãos das variedades estudadas. Ainda nas Figuras 2 e 3, observa-se que a equação,

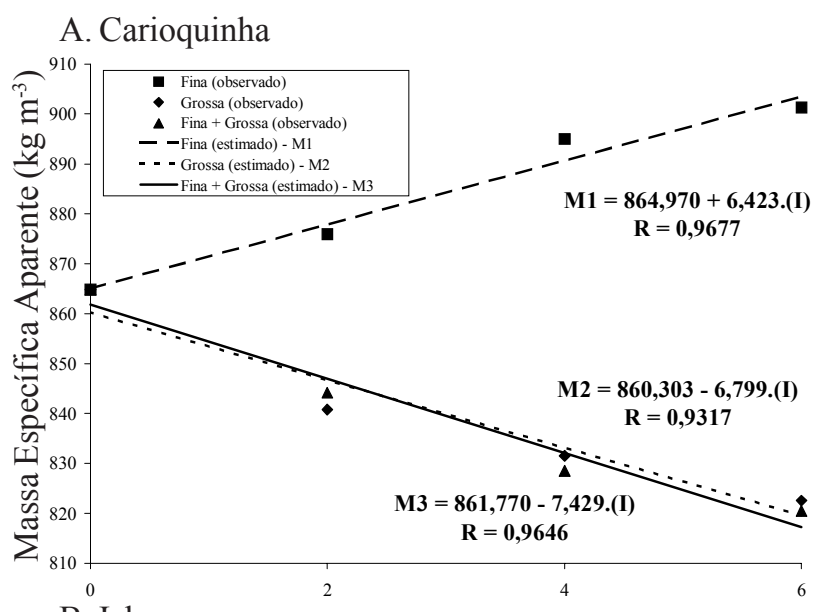

B. Jalo

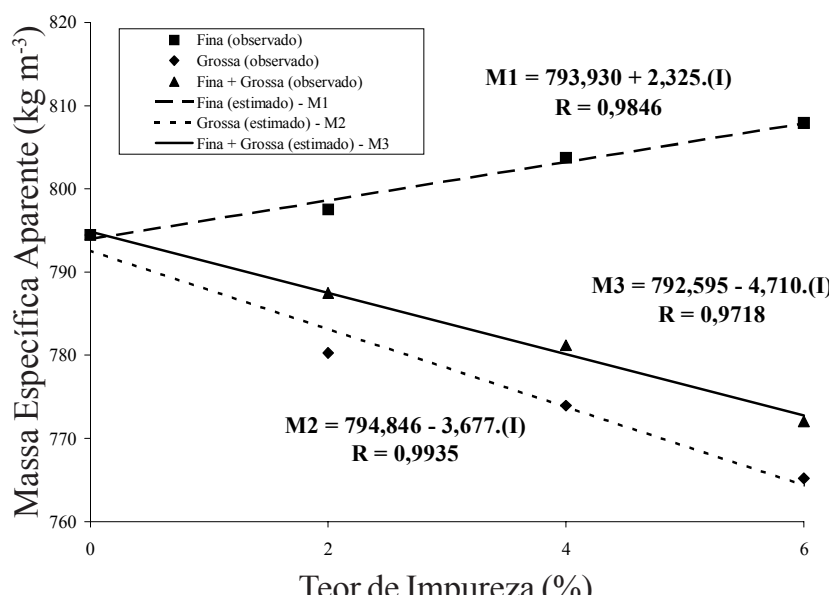

Figura 2. Valores experimentais e estimados de massa específica aparente (M) de grãos de feijão, em função do teor (I) e do tamanho de impurezas, para as variedades estudadas com teor de umidade de $12 \%$ b.u.
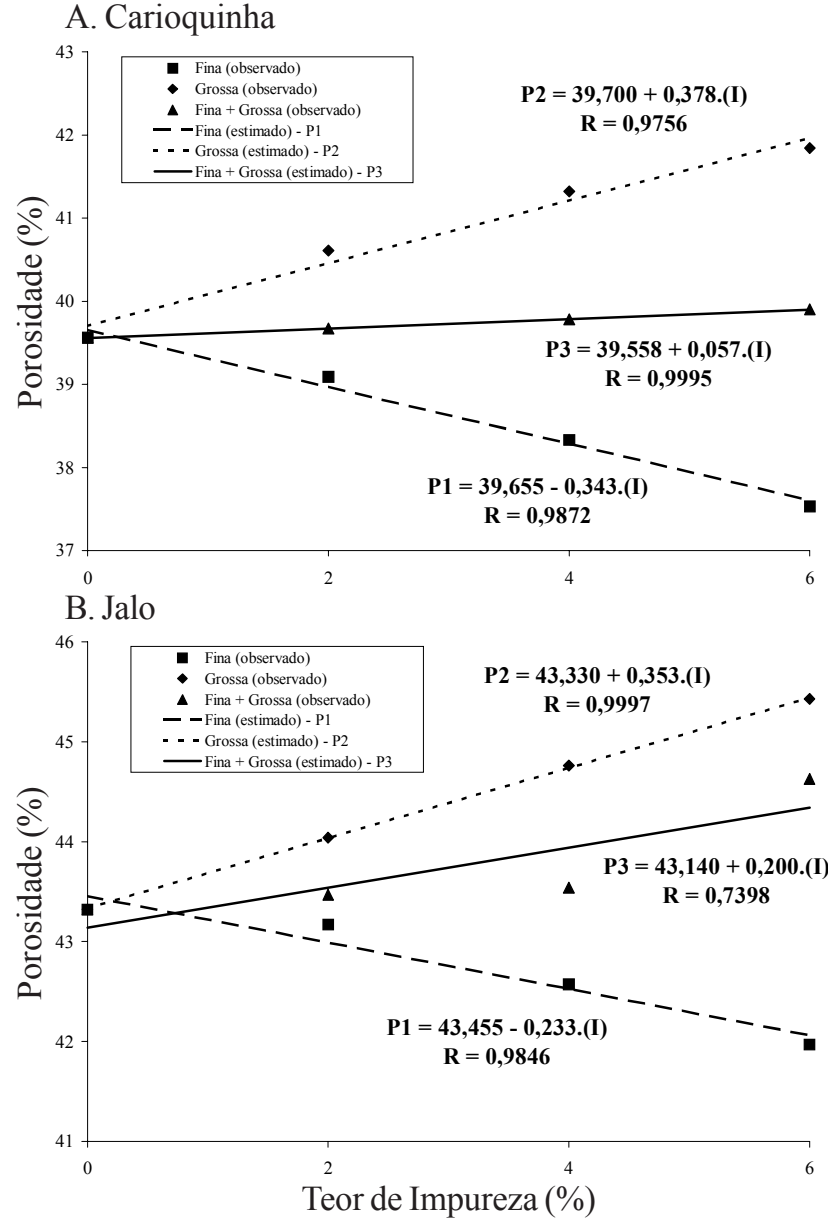

Figura 3. Valores experimentais e estimados de porosidade (P) de grãos de feijão, em função do teor (I) e do tamanho de impurezas, para as variedades estudadas com teor de umidade de $12 \%$ b.u. 0

com base no modelo linear, foi a que melhor se ajustou aos dados experimentais de massa específica aparente e porosidade das amostras de feijão, com elevados coeficientes de determinação, para o produto com $12 \%$ b.u.

Pelos dados obtidos e apresentados na Figura 2, verifica-se que a massa específica aparente do feijão da variedade Carioquinha é superior à da variedade Jalo, tanto para o produto limpo quanto para o acrescido de impurezas, o que se deve ao menor volume de espaços intergranulares da massa de feijão dessa variedade. A presença de impurezas finas provocou aumento diretamente proporcional na massa específica aparente das variedades estudadas, porém o acréscimo de impurezas grossas promoveu redução da massa específica aparente, para as duas variedades.

Verifica-se, ainda, que, para a situação em que o produto foi misturado a impurezas finas e grossas, na mesma proporção, os resultados encontrados foram intermediários. Torna-se importante ressaltar que a impureza fina utilizada nos testes foi a mesma nas duas variedades investigadas mas, em razão da grande diferença de tamanho entre o feijão da variedade Carioquinha e o da variedade Jalo, diferentes tamanhos de impureza grossa foram utilizados para realização dos testes. 
Pode-se observar, na Figura 3, que o feijão da variedade Jalo apresentou valores superiores para porosidade, quando comparado aos valores obtidos para variedade Carioquinha, mesmo quando acrescido de impurezas finas nas proporções estudadas. À medida que foram acrescentadas impurezas finas ao produto das duas variedades, ocorreu redução no percentual de espaços intergranulares, fato que refletiu diretamente sobre os valores de porosidade das amostras analisadas; verifica-se, ainda, que a mistura de impurezas grossas ao produto provocou aumento da porosidade e, quando misturado a impurezas finas e grossas, em quantidades iguais, o feijão das duas variedades apresentou comportamento semelhante ao observado para massa específica aparente, ou seja, resultados intermediários de porosidade.

Os resultados encontrados neste trabalho, mostrando que a massa específica aparente de grãos de feijão diminui e a porosidade aumenta com a elevação do nível de impurezas grossas e redução de impurezas finas, apresentam a mesma tendência da maioria dos resultados encontrados por diversos autores para diferentes produtos agrícolas (Haque et al., 1978; Sasseron, 1980; Grama et al., 1984; Jayas et al., 1991).

\section{CONCLUSÕES}

Os resultados obtidos neste trabalho permitiram concluir-se, para o produto com teor de umidade de $12 \%$ b.u., que:

1. O aumento do nível de impurezas finas, para as variedades Carioquinha e Jalo, provocou aumento da massa específica aparente e redução da porosidade da massa de produto.

2. O aumento do nível de impurezas grossas, para ambas as variedades, provocou redução da massa específica aparente e aumento da porosidade da massa de produto.

3. O feijão das duas variedades estudadas, quando acrescido da mistura de impurezas finas e grossas em partes iguais, apresentou comportamento intermediário da massa específica aparente e porosidade, quando comparado com os tratamentos com apenas um tamanho de impureza.

4. Os valores de massa específica aparente e porosidade da massa de grãos de feijão, diferiram entre as variedades analisadas, sendo os valores da massa específica aparente da cultivar Carioquinha superiores, enquanto os valores de porosidade apresentaram-se inferiores aos observados para a cultivar Jalo.

5. As equações ajustadas para predizer os valores de massa específica aparente e porosidade, em função do nível e do tamanho de impurezas na massa granular de feijão, representam, de forma satisfatória e com elevado coeficiente de determinação ajustado, o fenômeno estudado, podendo ser utilizadas para determinação dessas propriedades físicas de ambas as cultivares analisadas.

\section{AGRADECIMENTOS}

Os autores agradecem à FINEP/RECOPE, pelo auxílio financeiro.

\section{LITERATURA CITADA}

ASAE Standards 1998: Standards, engineering practices and data. 45 ed. St. Joseph: ASAE, 1998. 978p.

Benedetti, B.C. Influência do teor de umidade sobre propriedades físicas de vários grãos. Campinas: UNICAMP, 1987. 125p. Dissertação Mestrado

Brooker, D.B.; Bakker-Arkema, F.W.; Hall, C.W. Drying and storage of grains and oilseeds. New York: AVI, 1992.450p.

Chung, D.S.; Abdelmoshin, G.A.; Kim, M.S. Resistance of grain sorghum to airflow. Transactions of the ASAE. St. Joseph: 1984. 13p. Paper 84-3529.

CONAB - Companhia Nacional de Abastecimento. Indicadores da agropecuária. Brasília, ano VIII, n. 11, p.5-7, 1999.

Couto, S.M.; Magalhães, A.C.; Queiroz, D.M.; Bastos, I.T. Massa específica aparente e real e porosidade de grãos de café, em função do teor de umidade. Revista Brasileira de Engenharia Agrícola e Ambiental, Campina Grande, v.3, n.1, p.61-68, 1999.

Grama, S.N.; Bern, C.R.; Hurburgh Jr., C.R. Airflow resistance of mixtures of shelled and fines. Transactions of the ASAE, St. Joseph, v.27, n.1, p.268-272, 1984.

Haque, E.; Foster, G.H.; Chung, D.S.; Lai, F.S. Static pressure drop across a bed of corn mixed with fines. Transactions of the ASAE, St. Joseph, v.21, n.5, p.997-1000, 1978.

Jayas, D.S.; Alagusundaram, D.; Irvine, D.A. Resistance to airflow through bulk flax seed as affected by moisture content, direction of airflow and foreign material. Canadian Agricultural Engineering, Ottawa, v.32, n.2, p.279-285, 1991.

Mohsenin, N.N. Physical properties of plant and animal materials. New York: Gordon and Breach Science, 1970. v.1, 734p.

Moraes Neto, J.M. Determinação de parâmetros básicos de feijão carioquinha necessários ao modelamento matemático de secagem em camada espessa. Campina Grande: UFPB, 1991. 102p. Dissertação Mestrado.

Ramalho, M.A.P.; Abreu, A.F.B.; Andrade, M.J.B. Cultivares de feijão para o plantio no outono-inverno. Informe Agropecuário, Belo Horizonte, v.17, n.178, p.8-11, 1994.

Ruffato, S.; Corrêa, P.C.; Martins, J.H.; Mantovani, B.H.M.; Silva, J.N. Influência do processo de secagem sobre a massa específica aparente, massa específica unitária e porosidade de milho-pipoca. Revista Brasileira de Engenharia Agrícola e Ambiental, Campina Grande, v.3, n.1, p.45-48, 1999.

Sasseron, J.L. Características dos grãos armazenados. Viçosa, MG: CENTREINAR, 1980.65p.

Vieira, R.F.; Vieira, C.; Ramos, J.A.O. Produção de sementes de feijão. Viçosa, MG: EPAMIG,1993. 131p. 